\title{
Decontamination of chemical warfare sulfur mustard agent simulant by $\mathrm{ZnO}$ nanoparticles
}

\author{
Meysam Sadeghi $^{1} \cdot$ Sina Yekta $^{2} \cdot$ Hamed Ghaedi $^{3}$
}

Received: 13 November 2015 / Accepted: 25 June 2016/Published online: 4 July 2016

(c) The Author(s) 2016. This article is published with open access at Springerlink.com

\begin{abstract}
In this study, zinc oxide nanoparticles $(\mathrm{ZnO}$ NPs) have been surveyed to decontaminate the chloroethyl phenyl sulfide as a sulfur mustard agent simulant. Prior to the reaction, $\mathrm{ZnO}$ NPs were successfully prepared through sol-gel method in the absence and presence of polyvinyl alcohol (PVA). PVA was utilized as a capping agent to control the agglomeration of the nanoparticles. The formation, morphology, elemental component, and crystalline size of nanoscale $\mathrm{ZnO}$ were certified and characterized by SEM/EDX, XRD, and FT-IR techniques. The decontamination (adsorption and destruction) was tracked by the GCFID analysis, in which the effects of polarity of the media, such as isopropanol, acetone and $n$-hexane, reaction time intervals from 1 up to $18 \mathrm{~h}$, and different temperatures, including $25,35,45$, and $55^{\circ} \mathrm{C}$, on the catalytic/
\end{abstract}

decontaminative capability of the surface of $\mathrm{ZnO}$ NPs/PVA were investigated and discussed, respectively. Results demonstrated that maximum decontamination (100\%) occurred in $n$-hexane solvent at $55^{\circ} \mathrm{C}$ after $1 \mathrm{~h}$. On the other hand, the obtained results for the acetone and isopropanol solvents were lower than expected. GC-MS chromatograms confirmed the formation of hydroxyl ethyl phenyl sulfide and phenyl vinyl sulfide as the destruction reaction products. Furthermore, these chromatograms proved the role of hydrolysis and elimination mechanisms on the catalyst considering its surface Bronsted and Lewis acid sites. A non-polar solvent aids material transfer to the reactive surface acid sites without blocking these sites.

Meysam Sadeghi

meysamsadeghi1177@gmail.com

1 Young Researchers and Elite Club, Islamic Azad University, Ahvaz Branch, Ahvaz, Iran

2 Department of Chemistry, Faculty of Basic Sciences, Islamic Azad University, Qaemshahr Branch, Qaemshahr, Iran

3 Department of Engineering, Islamic Azad University, Bushehr Branch, Bushehr, Iran 


\section{Graphical Abstract}

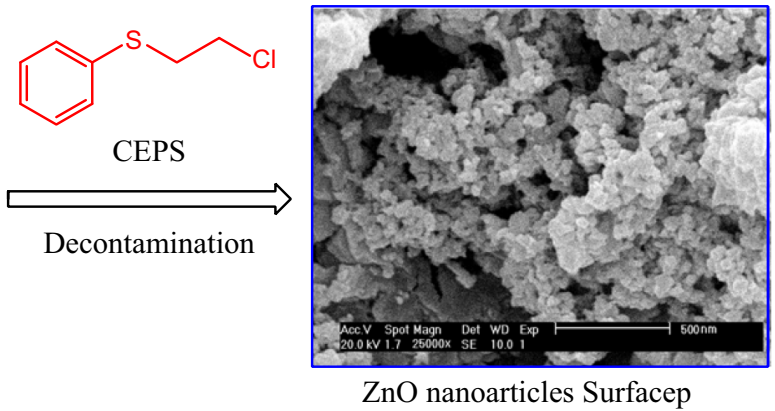

$\mathrm{ZnO}$ nanoarticles Surfacep

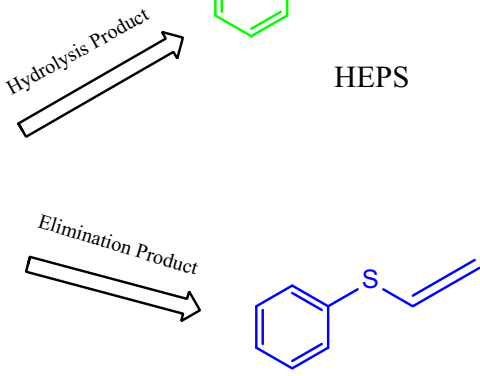

PVS
Keywords Zinc oxide nanoparticles · Decontaminate . Chloroethyl phenyl sulfide · Hydrolysis · Elimination

\section{Introduction}

The production and utilization of chemical warfare agents (CWAs) have been of great concern for worldwide community and known as a serious threat that must not be overlooked. The vexatious reports from Middle East and Syria during the last year have depicted the crisis of CWAs usage namely sulfur mustard and phosphorus nerve agents by terrorist organizations. These CWAs are cheap and easy to manufacture. Therefore, the devastating effects related to the military actions, large worldwide ammunition stock, and, especially, the probable terrorist attacks $[1,2]$ have attracted much tendency for catalytic decontamination of CWAs by introducing the new and highly reactive decontaminants. Over time, adsorption of the toxic agents and subsequently degradation and neutralization strategies have been emerged in the spotlight of researchers, necessarily for research in countering terrorism and military defense units. One of the most known CWAs is sulfur mustard (bis(chloroethyl)sulfide) with the molecular formula of $\left(\mathrm{ClCH}_{2} \mathrm{CH}_{2}\right)_{2} \mathrm{~S}$, commonly abbreviated as $\mathrm{H}$ for munition grade and $\mathrm{D}$ for distilled). Less-toxic analogues (simulants), such as chloroethyl phenyl sulfide (CEPS), with physicochemical properties similar to those of the agent could be generally subject to the research studies due to extreme toxicity of HD. The chemical structures of HD and CEPS are illustrated in Fig. 1. One of the main challenges for the decontamination of HD and its analogues is their permanency which makes them extremely hazardous. Being exposed to these compounds commonly brings about blistering of the skin and mucous membranes. Hence, they are socalled vesicants or blistering agents [3].

Many advances have been made so far to design methodologies and strategies to neutralize harmful CWAs. The very first and long-term methods were traditionally high aggressive chemicals, such as bleaching powder,

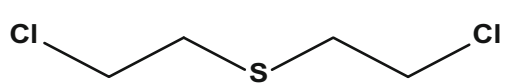

(a)

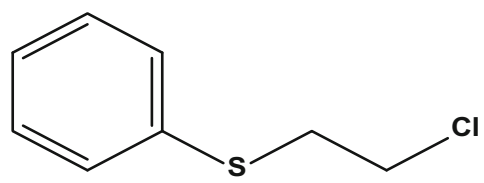

(b)

Fig. 1 Chemical structures of: a HD and b CEPS

potassium permanganate, $m$-chloroperoxybenzoic acid, magnesium monoperoxyphthalate, potassium persulfate, oxon, sodium hypochlorite, and hydrogen peroxide $\left(\mathrm{H}_{2} \mathrm{O}_{2}\right)$ [4]. However, due to the disadvantages associated with liquid detoxification, investigation for new decontaminants with no hazardous side effects has been started. Lately, reports have revealed that there is a great interest in use of solid sorbent decontaminants, such as nano metal oxides. Several nanocrystalline metal oxides, such as $\mathrm{CaO}$ [5], $\mathrm{MgO}$ [6-8], $\mathrm{Al}_{2} \mathrm{O}_{3}$ [6-9], and $\mathrm{ZnO}$ [10], have been synthesized as adsorbents and catalysts using in various scientific fields. One of the most notable fields is their utilization for multiple defense applications, such as nuclear, biological, chemical (NBC) warfare, destructive adsorption, and decomposition of acid gases and polar organics, including CWAs and their mimics [11-13].

Moreover, a lot of attention has been conducted toward improving the reactivity of metal oxides as solid adsorptive catalysts to replace the traditional liquid decontamination of HD and its simulants [14-18]. The investigations have proved metal oxide nanostructures as potential adsorbents for the catalytic decontamination of HD and its simulants [19-23]. Zinc oxide nanoparticles (ZnO NPs) are among the promising adsorbents widely used in environmental catalysis. ZnO NPs have also shown industrial applications, including gas sensing as a surface acoustic wave (SAW) 
sensor [24], semiconductor applicability with a wide gap energy $(3.3 \mathrm{eV})$ [25], photonic crystals [26], light emitting diodes [27], photo detectors and varistors [28], gas sensors [29], and solar cells [30]. ZnO NPs possess a relatively large number Lewis and Bronsted acid sites that cause a high adsorption capacity for a wide range of hazardous components. In this work, we have proposed a simple, facile, and low cost sol-gel technique as a feasible method $[11,18,31,32]$ for the synthesis of ZnO NPs with PVA acting as both reducing agent and structure director for the catalytic decontamination of CEPS. To understand the changes during the decontamination process, the effects, such as polarity, time, temperature, and kinetics, of the reaction were monitored. In addition, to prevent the increase in the particle size and size distribution, a reducing or capping agent, often a polymer is used, either natural or synthetic with a degree of affinity for metals. The polymer is adsorbed on the cluster in the solution and reduces the surface tension. These agents also control both the reduction rate of metal ions and the aggregation of final particles and further stabilize the colloidal particles in water and many non-aqueous solvents through adsorbing onto a broad range of materials, such as metals and metal oxides [33]. The decontamination reaction of CEPS includes a two-step reaction. First, the adsorption of analyte (CEPS molecule) on the surface of $\mathrm{ZnO}$ adsorbent nanoparticles and then its subsequent destruction. The main goal of the present research is to convert high toxic CEPS into non-toxic and safe products.

\section{Experiment}

\section{Chemicals}

Zinc nitrate hexahydrate $\left(\mathrm{Zn}\left(\mathrm{NO}_{3}\right)_{2} \cdot 6 \mathrm{H}_{2} \mathrm{O}, 99 \%\right)$, polyvinyl alcohol (PVA, $98 \%$ ), ethyl alcohol (ethanol, $99 \%$ ), isopropyl alcohol [isopropanol (IPA), $99 \%$ ], dimethyl ketone (acetone, $99 \%$ ), $n$-hexane (99\%), and methyl benzene (toluene, $99 \%$ ) were purchased from Merck (Merck, Darmstadt, Germany). The chloroethyl phenyl sulfide (CEPS, $98 \%$ ) was obtained commercially from Sigma-Aldrich Co. (USA). All chemicals were used as received and were of chemical grade. For the preparation of all the solutions, deionized water was used.

\section{Instrumentation}

To elucidate the physicochemical properties of the produced catalyst, different characterization techniques were used. The morphology and size of the prepared sample were recorded by a scanning electron microscope equipped with an Energy Dispersive X-ray Spectroscopy (SEM/EDX,
LEO-1530VP). The powder X-ray diffraction (XRD) analysis was carried out at room temperature on a Philips diffractometer equipped with $\mathrm{Cu} \mathrm{K} \alpha$ radiation and a wavelength of $0.15418 \mathrm{~nm}(20 \mathrm{kV}$ and $30 \mathrm{~mA})$. The data were collected over the range $30^{\circ}-70^{\circ}$ in $2 \theta$ with a scanning speed of $2^{\circ} \mathrm{min}^{-1}$. The IR spectrum was scanned on a PerkinElmer model 2000 FT-IR spectrometer (USA) in the wavelength range of $400-4000 \mathrm{~cm}^{-1}$ using $\mathrm{KBr}$ pellets. A Varian Star 3400CX series gas chromatograph equipped with flame ionization detector (GC-FID) and an OV101CWHP $80 / 100$ silica capillary column $[30 \mathrm{~m} \times$ $0.25 \mathrm{~mm}$ inner diameter (i.d.), $0.25 \mu \mathrm{m}$ film thickness, J\&W Scientific Inc., Rancho Cordova, CA, USA] was used to monitor the decontamination reactions of CEPS. The extracted products were analyzed by an HP-Agilent gas chromatograph-mass spectrometer equipped with a fusedsilica capillary column [DB 1701, $30 \mathrm{~m} \times 0.25 \mathrm{~mm}$ inner diameter (i.d.), $0.25 \mu \mathrm{m}$ film thickness]. In brief, the column temperature was initially held at $60{ }^{\circ} \mathrm{C}$ for $4 \mathrm{~min}$ and programmed at $20{ }^{\circ} \mathrm{C} \mathrm{min}-1$ to $220{ }^{\circ} \mathrm{C}$ for 13 min to reach the final temperature, which was then held for $6 \mathrm{~min}$. The injector, MS quad, and source temperatures were fixed at 60, 200, and $230{ }^{\circ} \mathrm{C}$, respectively. Helium (99.999\% purity) was selected as the carrier gas with the flow rate of $1 \mathrm{~mL} \mathrm{~min}{ }^{-1}$. The injection was performed in the split mode.

\section{Preparation of $\mathrm{ZnO}$ nanoparticles by sol-gel method}

In a typical sol-gel experiment, a $50: 50 \mathrm{v} / \mathrm{v}$ mixture of deionized water/ethanol as solvent was prepared. A portion of $87 \mathrm{~mL}$ was transferred into $200 \mathrm{~mL}$ Erlenmeyer flask and $2.5 \mathrm{~g}$ of $\mathrm{Zn}\left(\mathrm{NO}_{3}\right)_{2} \cdot 6 \mathrm{H}_{2} \mathrm{O}$ was added to the solvent. The obtained mixture was then kept under constant stirring at $200 \mathrm{rpm}$ for $10 \mathrm{~min}$ using a magnetic bar to completely dissolve the zinc nitrate. Subsequently, $9 \mathrm{~g}$ of PVA was added and while vigorously being stirred for $1 \mathrm{~h}$, the mixture was heated to $80{ }^{\circ} \mathrm{C}$ until a transparent white sol solution was formed. Afterwards, the obtained sol was slowly heated to evaporate the solvent and to produce a hard homogeneous gel. At the final stage, after cooling at room temperature over a period of $1 \mathrm{~h}$, the gel was transferred into a crucible and calcined at $600{ }^{\circ} \mathrm{C}$ for $10 \mathrm{~h}$ to obtain ZnO NPs powder [21, 32].

\section{Decontamination procedure of CEPS by ZnO NPs}

$10 \mu \mathrm{L}$ of toluene as the internal standard and $10 \mu \mathrm{L}$ of a $5: 1(\mathrm{v} / \mathrm{v})$ ratio of CEPS/ $\mathrm{H}_{2} \mathrm{O}$ were added to $5 \mathrm{~mL}$ of each solvent (isopropanol, acetone, and $n$-hexane) representing the optimized work solutions. To prevent the vaporization of the solvents, all of the above-mentioned solutions were kept in a tightly sealed $20 \mathrm{~mL}$ Erlenmeyer flask. All the samples were vortexed for 1 min to give blank samples. 
$0.35 \mathrm{~g}$ of $\mathrm{ZnO}$ NPs powder was then added to the above solutions. No efforts were made to control ambient light or humidity. To achieve a perfect adsorption and a complete reaction between nanoparticles and sulfur mustard simulant, all the samples were shaken for 1, 4, 6, 10, 14, and $18 \mathrm{~h}$ on a wrist-action shaker. After agitation of solution samples, they left until the precipitation process fulfilled. Finally, $10 \mu \mathrm{L}$ of upper solution of each samples brought out by a micro-syringe and injected to GC-FID and GCMS instruments for quantitative analysis [34].

\section{Results and discussion}

\section{Characterization of the catalyst}

\section{SEM study}

The morphology and structural size of the as-synthesized samples were investigated through magnification by SEM images in the absence and presence of PVA as depicted in Fig. $2 \mathrm{a}$ and $\mathrm{b}$. Analyzing the morphology aspect of nanoparticles indicates that the sample consists of quasispherical particles and that nanoscale particles have been derived via incorporation of PVA serving as both reducing agent and structure director. A primary purpose of introducing PVA was to protect the ZnO NPs from growing and agglomerating. With the introduction of PVA, zinc ions, or particles would coordinate with oxygen atom in PVA and a covered layer would generate on the surface of the particles. This layer inhibits the growth and agglomeration of the particles. The average crystalline size of ZnO NPs was observed to have nanometric dimensions (less than $100 \mathrm{~nm}$ ).

\section{EDX study}

To confirm the presence of zinc $(\mathrm{Zn})$ and oxygen $(\mathrm{O})$ as the only elementary components in the catalyst sample, elemental analysis via EDX spectroscopy was performed. As shown in Fig. 2, no unidentified peak related to foreign impurity was observed in EDX spectrum and the results have shown the purity and composition of $\mathrm{ZnO}$ NPs. These results confirm coexistence of 82.59 and $17.41 \mathrm{wt} \%$ zinc and oxygen in the prepared sample, respectively (Fig. 3).

\section{XRD pattern}

Phase purity and crystalline structure have been determined by XRD pattern, as shown in Fig. 4. The peaks referring to $\mathrm{ZnO}$ NPs occurred at scattering angles $(2 \theta)$ of $31.7770^{\circ}$, $34.4340^{\circ}, \quad 36.2600^{\circ}, \quad 56.6210^{\circ}, 62.925^{\circ}, 66.3790^{\circ}$, $67.9980^{\circ}$, and $69.1210^{\circ}$ corresponding to diffraction planes of (100), (002), (101), (102), (110), (103), (200), (112), and (201), respectively, that have been crystallized in the hexagonal wurtzite phase and are in good agreement with those of $\mathrm{ZnO}$ NPs with space groups of P63mc and lattice size of $3.2501 \AA$, ICSD card \# 01-079-2205. No characteristic peaks related to impurities were observed in the pattern during synthesis step. A definite line broadening of the scattering pattern in Fig. 4 is a demonstration upon which the synthesized $\mathrm{ZnO}$ NPs are in nanoscale range. The crystalline size of the prepared $\mathrm{ZnO}$ NPs was investigated via XRD measurement and line broadening of the peak at $2 \theta=30^{\circ}-70^{\circ}$ using Debye-Scherrer Equation [35].

$d=\frac{K \lambda}{\beta \cos \theta}$,

where $d$ is the crystal size, $K$ is so-called shape factor which usually takes a value of $0.94, \lambda$ is the wavelength of $\mathrm{X}$-ray source, $\beta$ is the full width at half maximum (FWHM), and $\theta$ is Bragg diffraction angle. Using this equation, the average crystalline was calculated about $25 \mathrm{~nm}$. The size obtained from XRD measurement is consistent with the results from the SEM study.
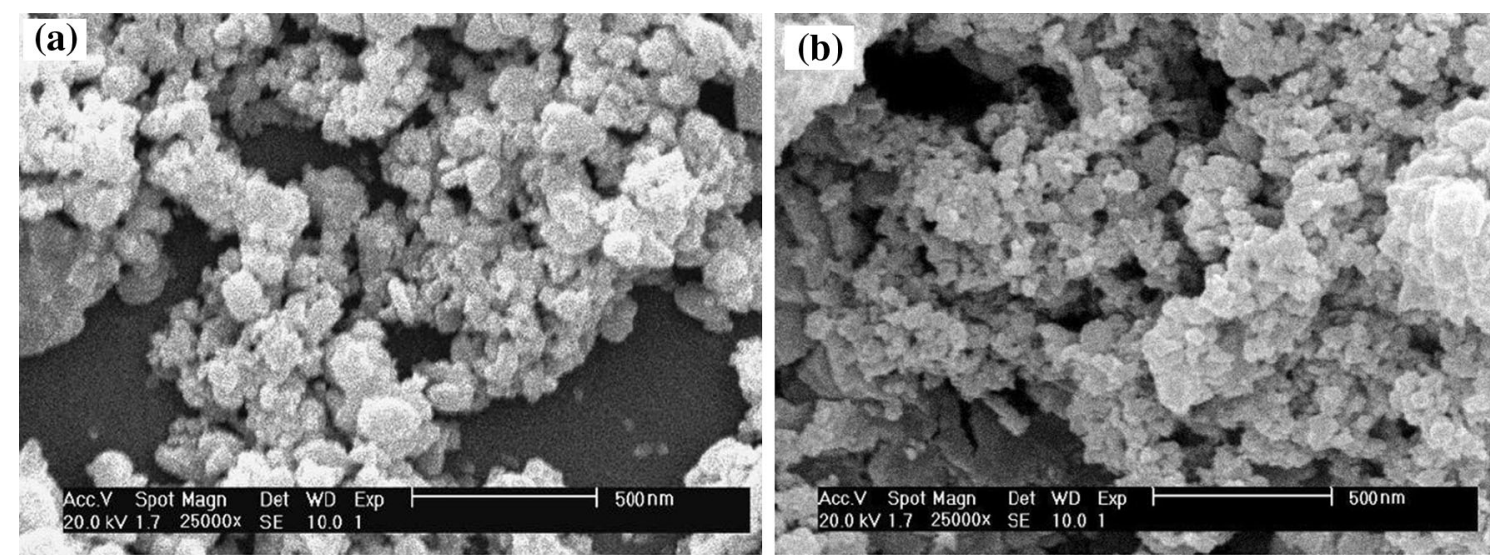

Fig. 2 SEM images of $\mathrm{ZnO}$ NPs in the $\mathbf{a}$ absence and $\mathbf{b}$ presence of PVA 
Fig. 3 EDX spectrum of the $\mathrm{ZnO}$ NPs

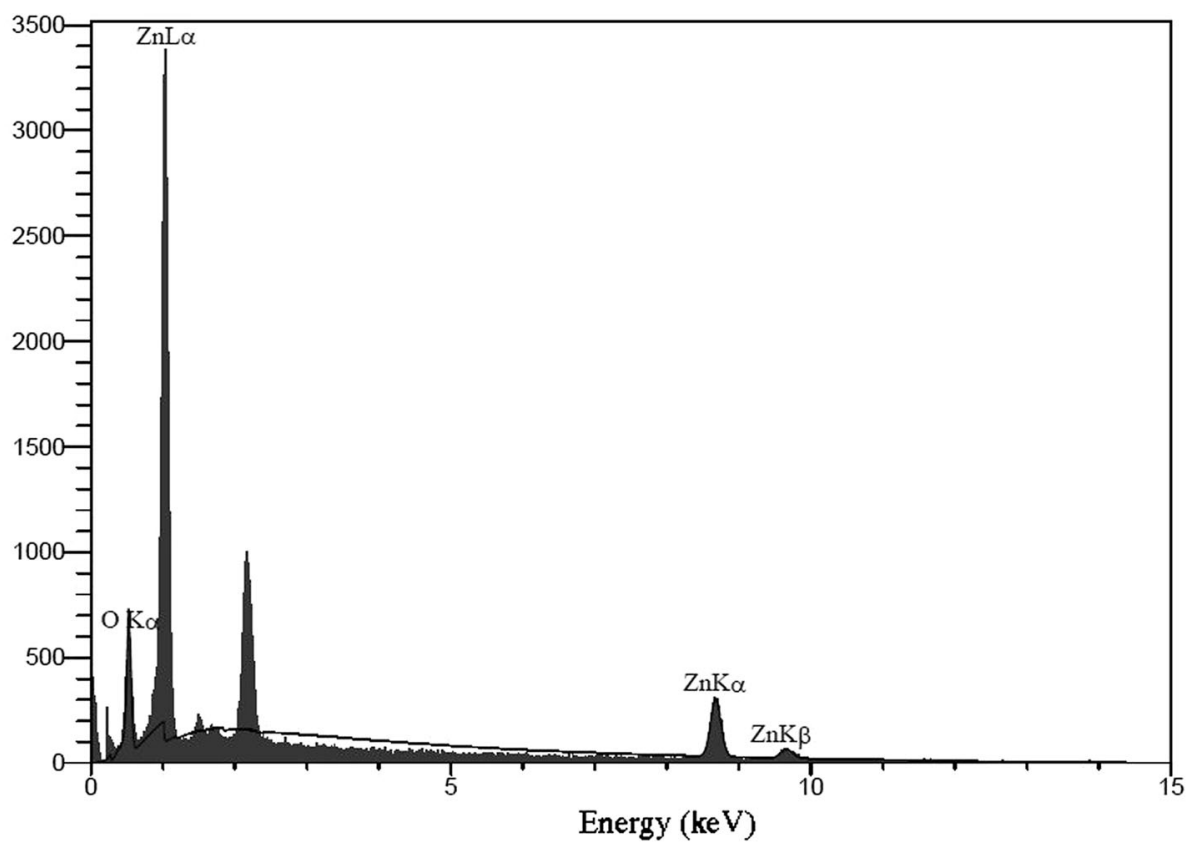

Fig. 4 XRD patterns of $\mathrm{ZnO}$ NPs

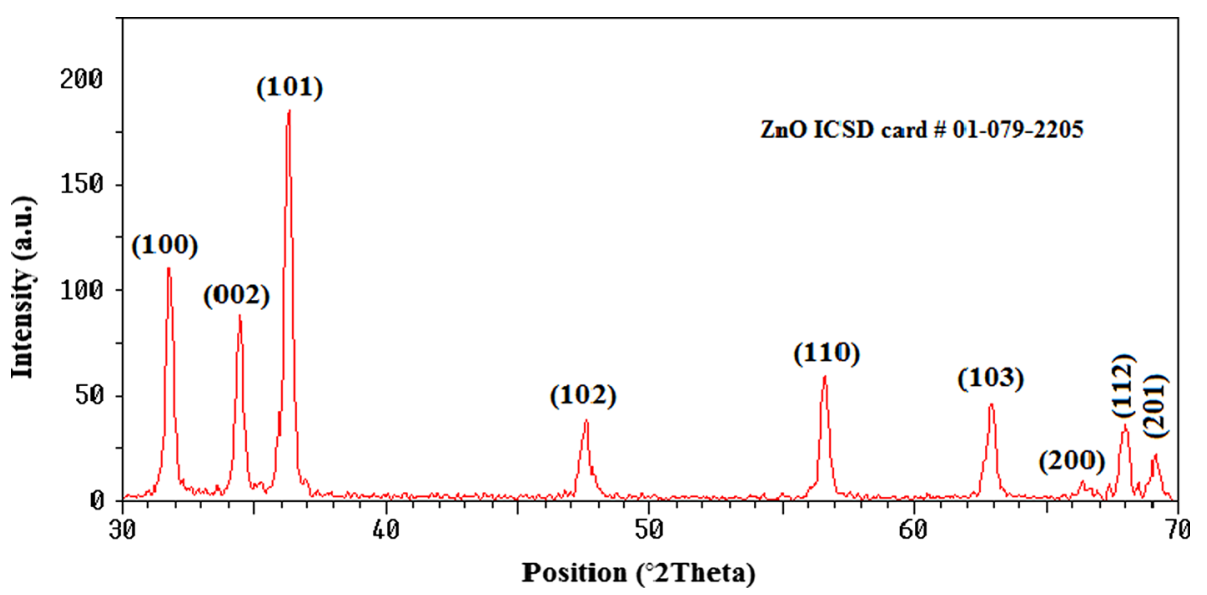

\section{FT-IR study}

The characterization of the prepared ZnO NPs was further surveyed by FT-IR spectroscopy. As depicted in Fig. 5, the strong absorbed peak at $450 \mathrm{~cm}^{-1}$ clearly indicates the formation of an interfacial chemical bond between zinc and oxygen. The characteristic absorb peak at $1149 \mathrm{~cm}^{-1}$ is corresponded to $\mathrm{C}-\mathrm{C}$ bonding vibrations in the synthesized sample. The peak at $1634 \mathrm{~cm}^{-1}$ can be related to adsorbed atmospheric $\mathrm{CO}_{2}$ and moisture or due to the present of solvent remained within the powder on the surface of metallic particles. In addition, the absorption peak displayed at $3449 \mathrm{~cm}^{-1}$ is assigned to hydroxyl $(\mathrm{O}-\mathrm{H})$ stretching vibration [36-38].

\section{GC analysis}

Catalytic performance of $\mathrm{ZnO}$ NPs for the decontamination reactions of CEPS as the deputy of sulfur mustard agent was evaluated at room temperature, and those progresses were monitored by GC-FID analysis. To accede maximum efficiency, the effects of influencing parameters, such as polarity of the media and the choice of solvent type, reaction time, and temperature, have been explored through utilizing isopropanol, acetone, and $n$-hexane as solvents, a $0-18 \mathrm{~h}$ range as shaking time and a $25-55^{\circ} \mathrm{C}$ range for the temperature of the reaction, respectively. GC chromatograms, the area under curve (AUC) data results under above parameters are summarized in Figs. 6, 7, 8, 9, 10, 11, 
Fig. 5 FT-IR spectrum of $\mathrm{ZnO}$ NPs

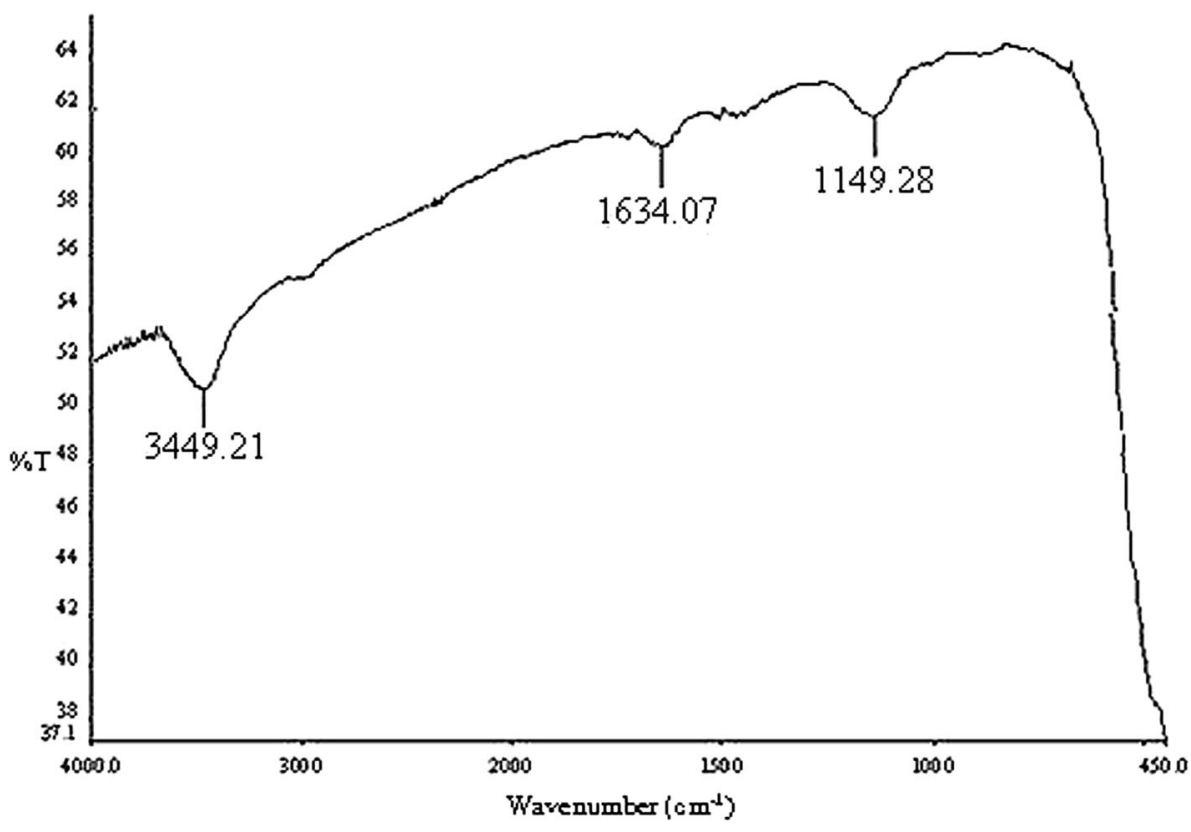

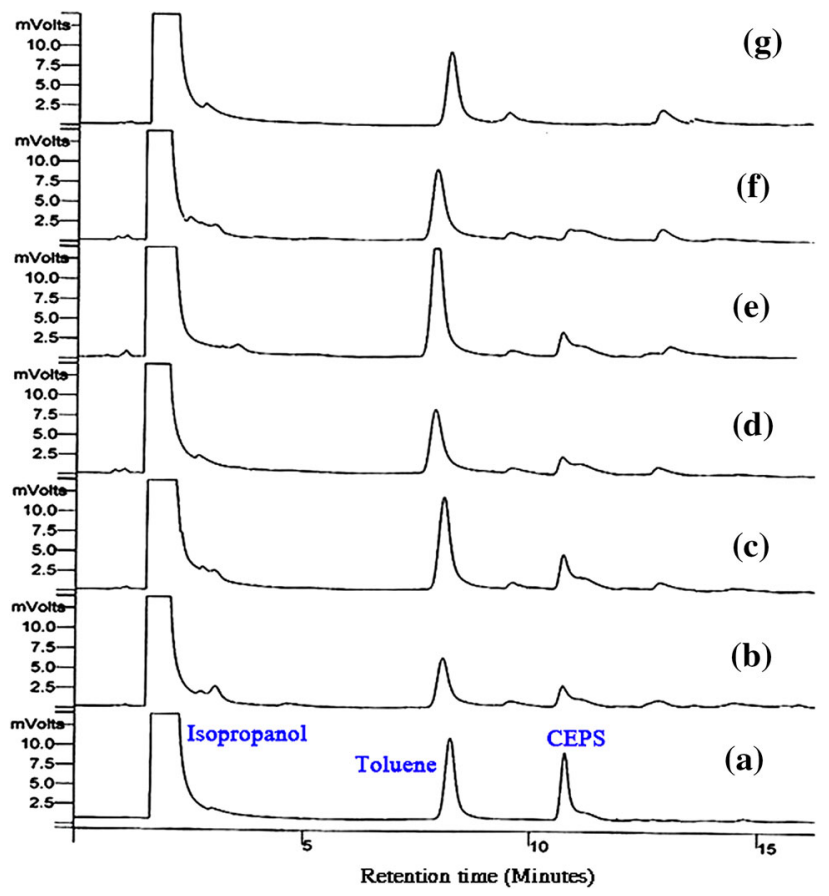

Fig. $6 \mathrm{GC}$ chromatograms for the $\mathrm{ZnO} / \mathrm{CEPS}$ sample at different times, a $0, \mathbf{b} 1, \mathbf{c} 4, \mathbf{d ~} 6$, e $10, \mathbf{f ~} 14, \mathbf{g ~} 18 \mathrm{~h}$, in isopropanol solvent

and 12. It is observed from the GC chromatograms that CEPS have a retention time at about $10.5 \mathrm{~min}$. To calculate the amounts of destruction, the integrated AUC data of two samples, CEPS and toluene, as the internal standard for all variables were measured and its ratio (integrated AUC of CEPS/integrated AUC of toluene) was determined. The results are shown in Fig. 7. Results have demonstrated that

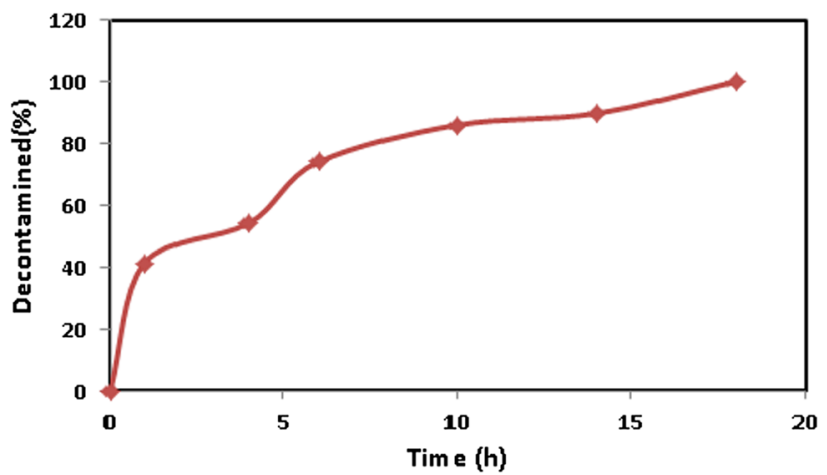

Fig. 7 Diagram of decontaminated CEPS\% versus time

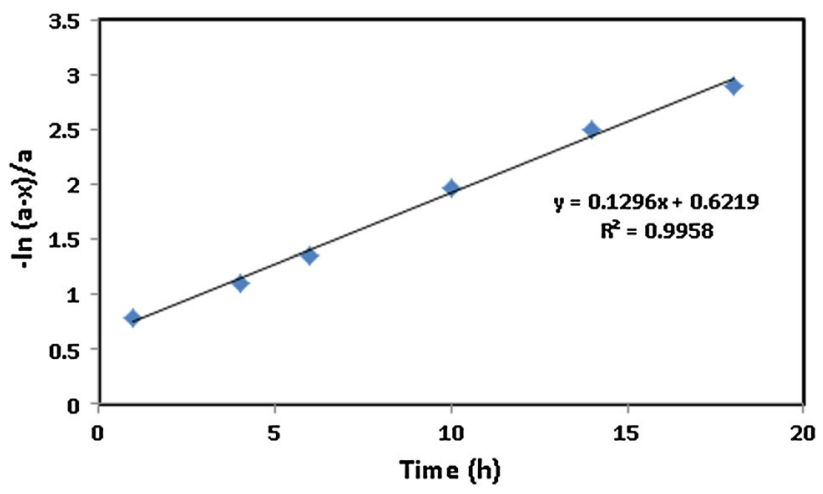

Fig. 8 Diagram of $-\ln (a-x) / a$ versus time

with decrease in polarity along with increasing the time and temperature, the intensity of the AUC data of CEPS was declined respect to that of toluene, and higher amounts of this molecule were decontaminated, which are illustrated 


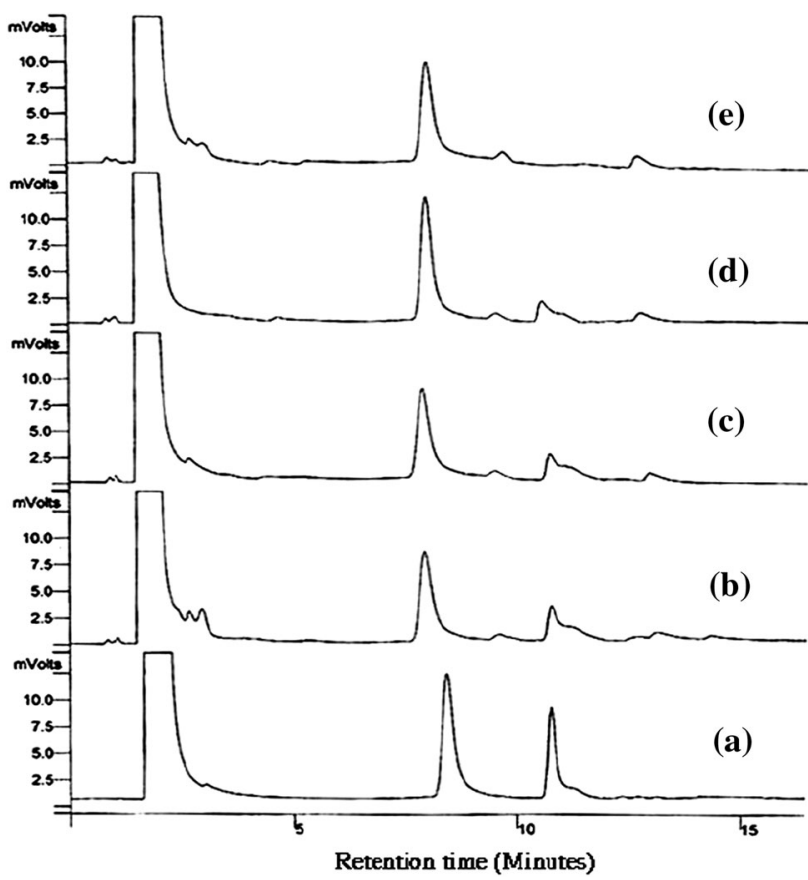

Fig. $9 \mathrm{GC}$ chromatograms for the $\mathrm{ZnO} / \mathrm{CEPS}$ sample at temperatures a $25{ }^{\circ} \mathrm{C}$, b $25{ }^{\circ} \mathrm{C}$, c $35{ }^{\circ} \mathrm{C}$, d $45{ }^{\circ} \mathrm{C}$, e $55^{\circ} \mathrm{C}$, in isopropanol solvent

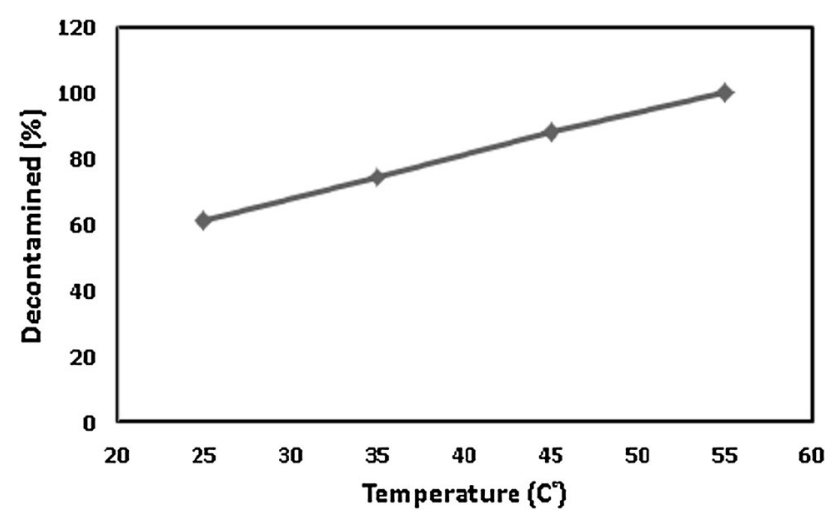

Fig. 10 Diagram of decontaminated CEPS\% versus temperature

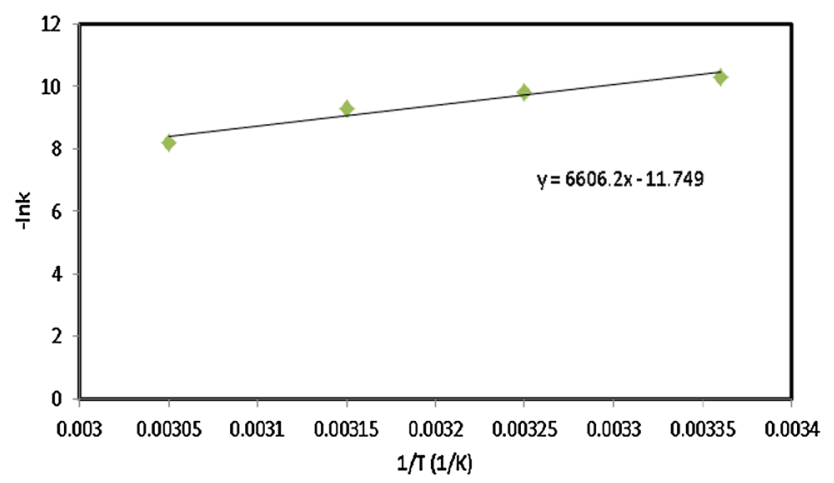

Fig. 11 Diagram of $-\ln k$ versus $1 / T$ by new peaks at retention times of 9.6 and $12.5 \mathrm{~min}$ referring to the products, respectively. Finally, the experiments clearly noted that the perfect decontamination $(100 \%)$ occurred in $n$-hexane at $55^{\circ} \mathrm{C}$ after $1 \mathrm{~h}$.

It should be considered that the base sites exist on the surface of metal oxides, no matter, the surface is acidic, basic, or neutral [5]. Thus, these sites will not withstand in polar solutions, because the polarity of solution interferes with polar reactions between analyte and transition sites of adsorbent which both are polar. Therefore, as comprehended from above, the polar solvents hinder the reaction's progress. It could be construed from the GC analysis that polar solvent can cover the reactive sites presented on the surface of $\mathrm{ZnO}$ NPs, including Bronsted and Lewis sites. Although the presence of high polarity poisons the adsorption sites, directly adding slight amount of $\mathrm{H}_{2} \mathrm{O}$ into the surface of $\mathrm{ZnO}$ NPs would activate the Bronsted acid sites and accelerate the decontamination of CEPS. Positive water effect was also observed for the decontamination of sulfur mustard agent in literature [24]. In particular, despite of a large number of strong Lewis acid sites originated from high surface area nanostructured $\mathrm{ZnO}$, the blocking of these adsorptive sites would hinder the coordination of CEPS. Since isopropanol is considered as such a strong hindrance to the reaction, this tends to lend further support to the idea that methanol simply blocks access to the surface of the catalyst. Thus, further reactions were investigated in $n$-hexane solvent.

Surveying the reaction between ZnO NPs and CEPS through GC analysis showed that if one allows for enough time, complete destructive catalysis would readily occur. In fact, $100 \%$ of CEPS was adsorbed and destructed by the catalyst after $18 \mathrm{~h}$. Diagrams illustrating the amount of decontamination and $-\ln (a-x) / a$ versus time in Fig. 6 point out to the fact that reaction time induces a kinetic effect, in which the number and vicinity of reactive sites with CEPS molecules making them adsorb and destruct, access to these sites and their catalytic capacity increase with time. In Fig. 8, the parameter (a) refers to the state when the amount of CEPS is virgin and unreacted with $\mathrm{ZnO}$ NPs and the parameter $(x)$ related to the beginning of CEPS reaction with $\mathrm{ZnO}$ NPs till the end of reaction, in which the CEPS is perfectly decontaminated up to 100 percent. Figure 8 has been drawn according to the data which has obtained from Fig. 7. In Fig. 7, decontaminated CEPS\% was utilized for the calculation of $-\ln (a-x) / a$ versus reaction time which has mentioned in Fig. 8. The linearity in diagram 7 elucidates that the kinetics of the reaction is of first order. The average rate constant and reaction half-life using slope of the diagram were measured as $3.60 \times 10^{-5} \mathrm{~min}^{-1}$ and $1.92 \times 10^{4} \mathrm{~min}$, respectively. Similar experiments in $n$-hexane solvent at higher temperatures $\left(35,45\right.$, and $\left.55^{\circ} \mathrm{C}\right)$ were taken to follow the 
Fig. 12 GC chromatograms for the $\mathrm{ZnO} / \mathrm{CEPS}$ sample at different solvents: a and $\mathbf{b}$ isopropanol, $\mathbf{c}$ and $\mathbf{d}$ acetone, and $\mathbf{e}$ and $\mathbf{f} n$-hexane

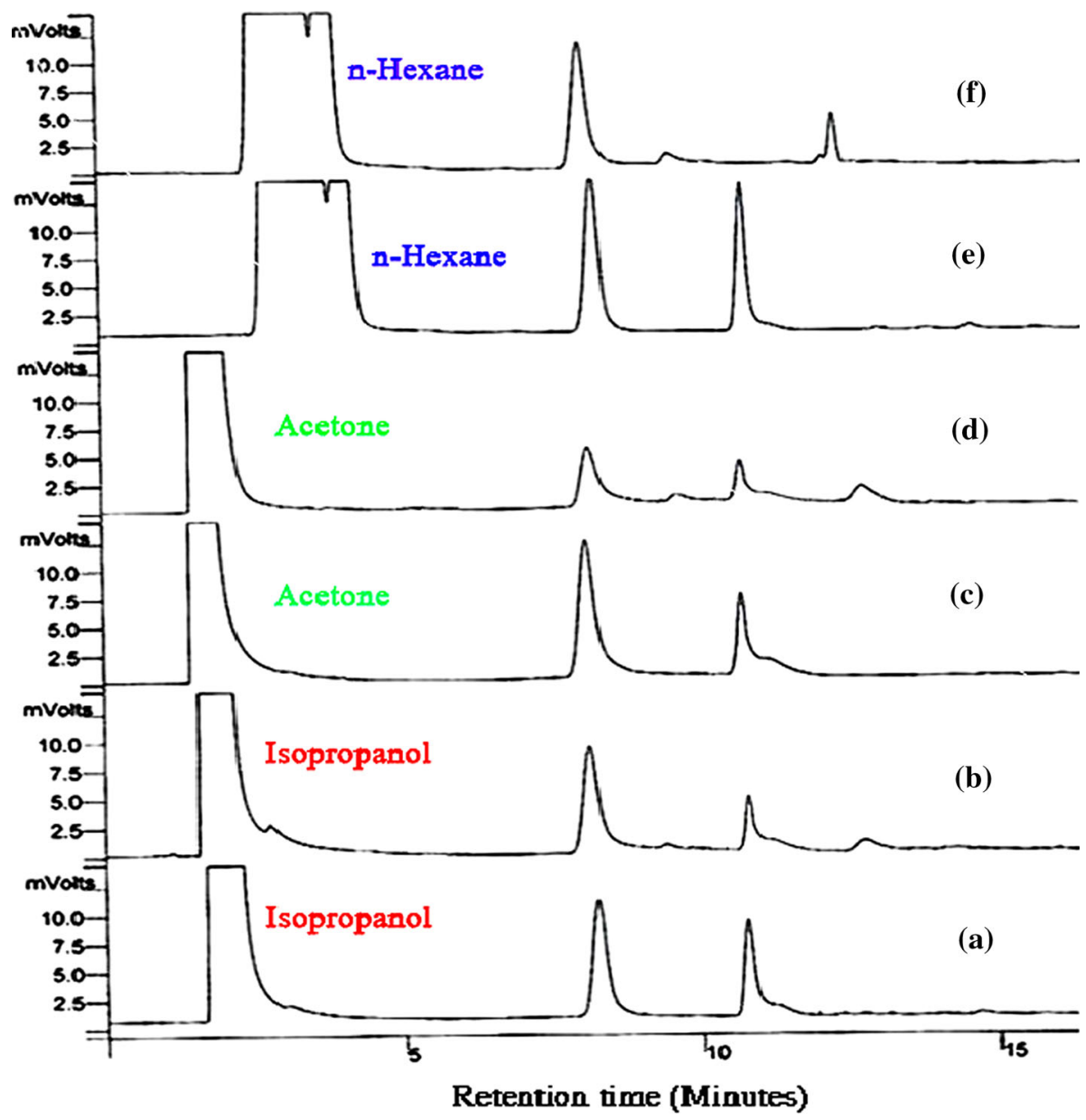

effect of temperature on the adsorption/destruction behavior of $\mathrm{ZnO}$ NPs. It was shown that $100 \%$ decontamination carried out at $55^{\circ} \mathrm{C}$ after $1 \mathrm{~h}$. The reason lies in the increase of reaction rate at higher temperatures. Moreover, thermal decomposition of the mustard simulant may arise at higher temperatures, which leads to its further destruction. Increasing the temperature alters Bronsted and Lewis sites both in number and strength and, also, the distinctness aspects of the surface structure. Changes in CEPS decontamination with temperature are demonstrated in Fig. 9a, in which using $\left(k_{T+10} / k_{T}\right)$, thermal constants between temperatures of $25,35,45$, and $55^{\circ} \mathrm{C}$ were calculated as 1.65 , 1.70 , and 2.86 , respectively. The average activation energy of the reaction via diagram of $-\ln k$ versus $1 / T$ and its slope was obtained as $56.427 \mathrm{~kJ} \mathrm{~mol}^{-1}$ (Fig. 11). In addition, rate constants and amounts of half-life of the adsorption/ destruction reactions of CEPS on the surface of $\mathrm{ZnO}$ NPs in the studied temperatures are brought in Table 1. The Eq. 2 in below is used for the calculation of half-life of the
Table 1 Rate constant and half-life for the ZnO/CEPS sample at different temperatures in isopropanol solvent

\begin{tabular}{rll}
\hline Half-life $(\mathrm{s})$ & Rate constant $\left(\mathrm{s}^{-1}\right)$ & $T\left(\mathrm{C}^{\circ}\right)$ \\
\hline $2.08 \times 10^{+4}$ & $3.3 \times 10^{-5}$ & $25 \pm 1$ \\
$1.2 \times 10^{+4}$ & $5.5 \times 10^{-5}$ & 35 \\
$7.45 \times 10^{+3}$ & $9.3 \times 10^{-5}$ & 45 \\
$2.6 \times 10^{+3}$ & $2.7 \times 10^{-7}$ & 55 \\
\hline
\end{tabular}

reaction. In this formula, parameter $(k)$ is defined as diagram slope of $-\ln k$ versus $1 / T$ which equals to rate constant

$t_{1 / 2}=0.693 / k$.

GC-MS analysis

Once the sulfur mustard simulant reacted on the surface of $\mathrm{ZnO} \mathrm{NPs}$, the identification and quantification of 

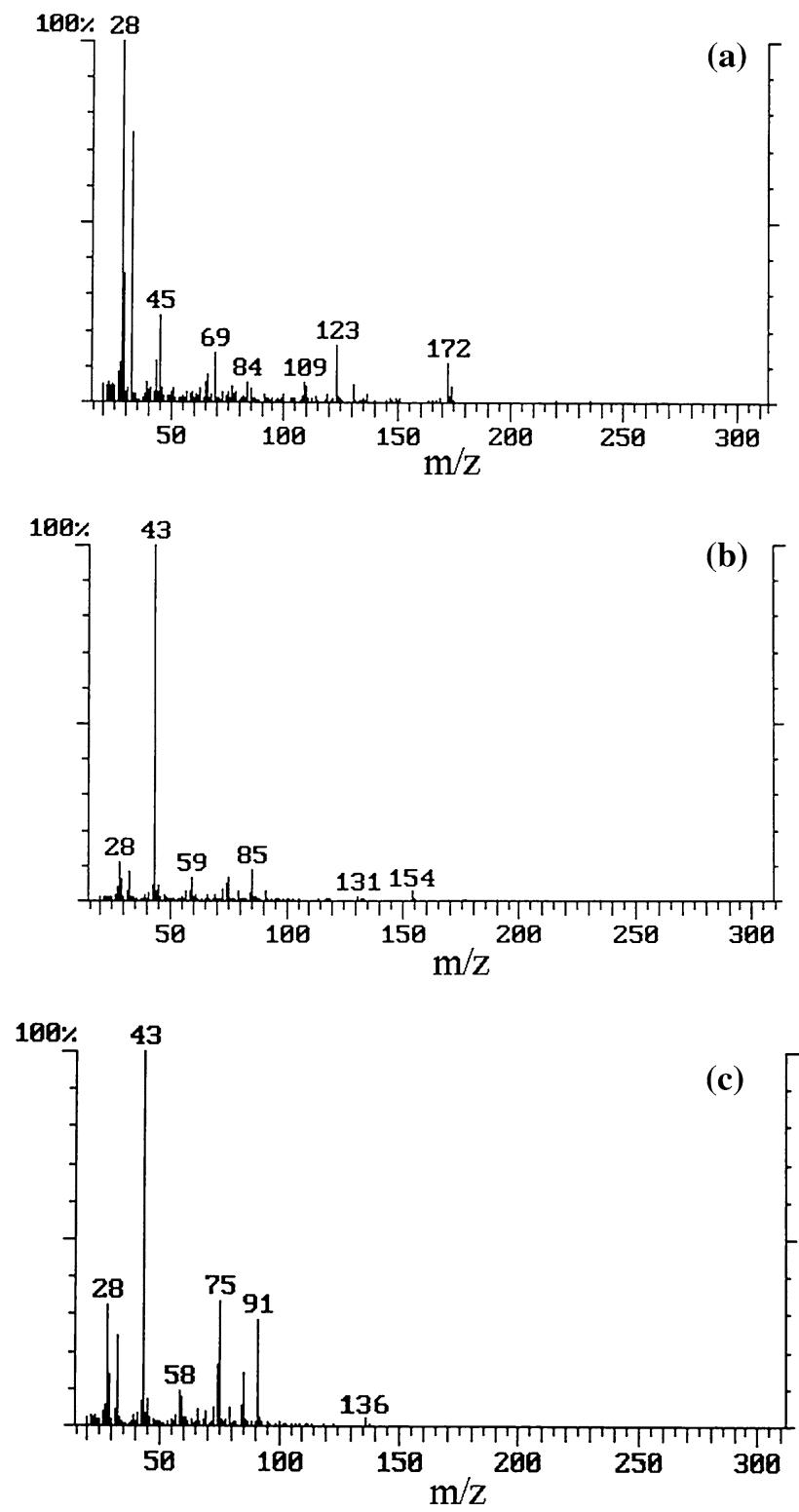

Fig. 13 Mass spectra from the GC-MS analysis of: a CEPS, b HEPS, and $\mathbf{c}$ PVS

destruction products, including HEPS and PVS, were followed by the GC-MS analysis. The detector was set to scan a mass range of $28-172,28-154$, and $28-136(\mathrm{~m} / \mathrm{z})$ for CEPS, HEPS, and PVS molecules, respectively, as depicted by the mass spectra in Fig. 13. The formation of the above less-toxic products emphasizes the role of hydrolysis and elimination reactions in the decontamination procedure.

\section{Mechanism of the decontamination procedure}

Based on the observations provided by the GC and GC-MS analyses, the mechanism scheme reflecting the decontamination chemistry (adsorption and destruction) of the sulfur mustard agent simulant on the catalyst along with the formation of destruction products is proposed (Fig. 14), in which the decontamination reactions through zinc species $\left(\mathrm{Zn}^{2+}\right)$ have been reviewed. It is worth noting that one of the proposed routes is possible and may proceed simultaneously.

In this route, adsorption reaction of sulfur mustard simulant occurs through nucleophillic attack of the Bronsted [hydroxyl groups $(\mathrm{Zn}-\mathrm{OH})$ ] acid sites presented on the $\mathrm{ZnO}$ of the external surface of the nanoparticles to chlorine and sulfur atom of CEPS molecule (initially, cyclic sulfonium ion seems to be formed as an intermediate which is in the non-volatile form of the related compound, so that could not be extracted out and detected by GC). Shortly after that, the chlorine atom in CEPS molecule will be removed through the dehalogenation reaction. In the presence and absence of $\mathrm{H}_{2} \mathrm{O}$ molecule, different reactions may proceed and hydrolysis and elimination products on the surfaces of $\mathrm{Zn}^{2+}$ as Lewis acid sites will be revealed. Both hydrolysis and elimination processes take place to yield hydroxyl ethyl phenyl sulfide (HEPS) and phenyl vinyl sulfide (PVS) as the destruction products of CEPS. Similar results were also observed by other researchers in several studies [10, 21-24, 39, 40].

\section{Conclusion}

In this study, ZnO NPs were prepared through the sol-gel method with PVA as reducing agent and structure director and then characterized by the SEM/EDX, XRD, and FTIR techniques. Thereafter, it was employed as catalyst to survey the decontamination (adsorption and destruction) of CEPS as a sulfur mustard agent simulant. The decontamination reactions were evaluated at different experimental conditions, including various solvents (polar and non-polar), time intervals, and temperatures, to elucidate their effects on the adsorption process and the interactions between CEPS agent simulant and reactive acid sites on the surface of $\mathrm{ZnO}$ NPs. Plus, kinetics and rate of the reaction, and changes in the number and strength of reactive adsorption sites and also needed activation 
Fig. 14 Proposed mechanism for the decontamination of CEPS on the $\mathrm{ZnO}$ NPs

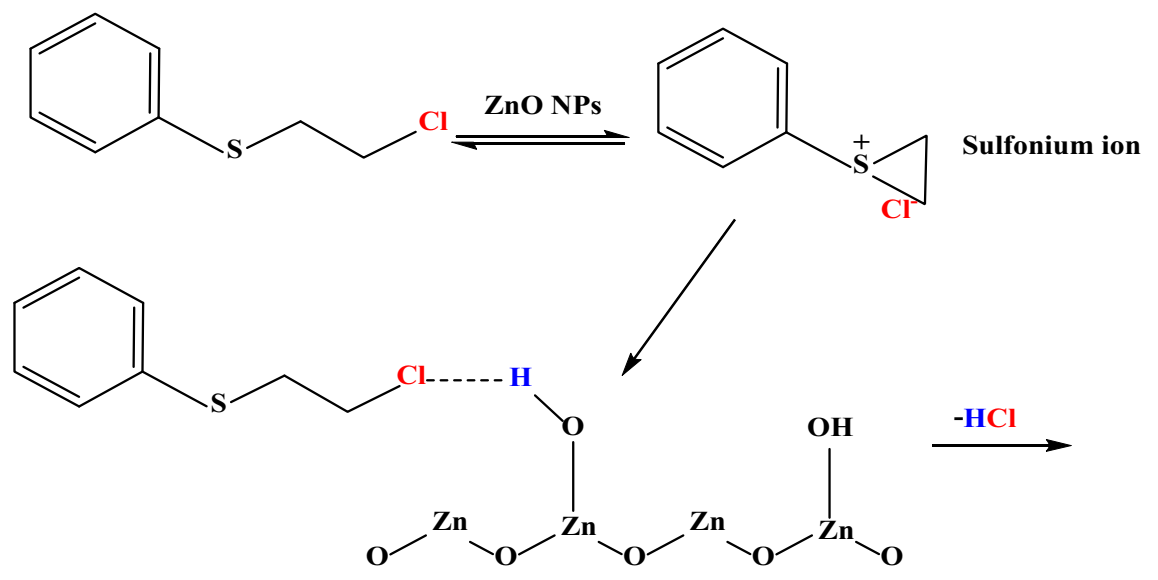<smiles>C=CSc1cccc(OCCO[Al]O[Ga]O[Al]2OCCSc3ccccc32)c1</smiles><smiles>OCCSc1ccccc1</smiles>

energy for destruction can be comprehend from abovementioned evaluation. The observations obtained by the $\mathrm{GC}$ analysis confirmed the high catalytic potential of $\mathrm{ZnO}$ NPs and also revealed that complete decontamination $(100 \%)$ occurred in $n$-hexane solvent after $1 \mathrm{~h}$ at $55^{\circ} \mathrm{C}$. After adsorption of CEPS, the non-toxic products of destruction reaction, i.e., hydrolysis and elimination, namely HEPS and PVS were also identified by the GCMS analysis. Thus, from this study, it can be inferred that the prepared $\mathrm{ZnO}$ NPs have high potential for further modifications to be utilized for more decontamination purposes in near future.

Acknowledgments The authors grant sincere thanks to the Islamic Azad University, Ahvaz, Iran, and Islamic Azad University, Qaemshahr, Iran, for all their supports.
Open Access This article is distributed under the terms of the Creative Commons Attribution 4.0 International License (http://creative commons.org/licenses/by/4.0/), which permits unrestricted use, distribution, and reproduction in any medium, provided you give appropriate credit to the original author(s) and the source, provide a link to the Creative Commons license, and indicate if changes were made.

\section{References}

1. Chauhan, S., Chauhan, S., D'Cruz, R., Faruqi, S., Singh, K.K., Varma, S., Singh, M., Karthik, V.: Chemical warfare agents. Environ. Toxicol. Pharm. 26, 113-122 (2008)

2. Wellert, S., Imhof, H., Dolle, M., Altmann, H.J., Richardt, A., Hellweg, T.: Decontamination of chemical warfare agents using perchloroethylene-Marlowet $\mathrm{IHF}-\mathrm{H}_{2} \mathrm{O}$-based microemulsions: wetting and extraction properties on realistic surfaces. Colloid Polym. Sci. 286, 417-426 (2008) 
3. Munro, N.B., Talmage, S.S., Griffin, G.D.: The sources, fate, and toxicity of chemical warfare agent degradation products. Environ. Health. Perspect. 107, 933-974 (1999)

4. Singh, R., Gutch, P.K., Acharya, J., Prabha, S.: Detoxification of $O, S$-diethyl methyl phosphonothiolate (OSDEMP), a simulant of VX, by $N, N$-dichlorourethane as an effective decontaminating agent. Indian J. Chem. 50, 1504-1509 (2011)

5. Wagner, G.W., Koper, O.B., Lucas, E., Decker, S., Klabunde, K.J.: Reactions of VX, GD, and HD with nanosize $\mathrm{CaO}$ : autocatalytic dehydrohalogenation of HD. J. Phys. Chem. 104, 5118-5123 (2000)

6. Dadvar, S., Tavanai, H., Morshed, M., Ghiaci, M.: A study on the kinetics of 2-chloroethyl ethyl sulfide adsorption onto nanocomposite activated carbon nanofibers containing metal oxide nanoparticles. Sep. Purif. Technol. 114, 24-30 (2013)

7. Wagner, G.W., Bartram, P.W., Koper, O., Klabunde, K.J.: Reactions of VX, GD, and HD with nanosize MgO. J. Phys. Chem. 103, 3225-3228 (1999)

8. Prasad, G.K., Mahato, T.H., Pandey, P., Singh, B., Suryanarayana, M.V.S., Saxena, A., Shekhar, K.: Reactive sorbent based on manganese oxide nanotubes and nanosheets for the decontamination of 2-chloro-ethyl ethyl sulphide. Microporous Mesoporous Mater. 106, 256-261 (2007)

9. Wagner, G.W., Procell, L.R., O'Connor, J.R., Munavalli, S., Carnes, C.L., Kapoor, P.N., Klabunde, K.J.: Reactions of VX, $\mathrm{GB}$, GD, and $\mathrm{HD}$ with nanosize $\mathrm{Al}_{2} \mathrm{O}_{3}$, formation of aluminophosphonates. J. Am. Chem. Soc. 123, 1636-1644 (2001)

10. Mahato, T.H., Prasad, G.K., Singh, B., Acharya, J., Srivastava, A.R., Vijayaraghavan, R.: Nanocrystalline zinc oxide for the decontamination of sarin. J. Hazard. Mater. 165, 928-932 (2009)

11. Hosono, H.: Recent progress in transparent oxide semiconductors: materials and device application. Thin Solid Films 515, 6000-6014 (2007)

12. Vidyasagar, C.C., Arthoba, N.Y., Venkatesh, T.G., Viswanatha, R.: Solid-state synthesis and effect of temperature on optical properties of $\mathrm{Cu}-\mathrm{ZnO}, \mathrm{Cu}-\mathrm{CdO}$ and $\mathrm{CuO}$ nanoparticles. Powder Technol. 214, 337-343 (2011)

13. Klingshirn, C.: ZnO: material, physics and applications. Chem. Phys. Chem. 8, 782-803 (2007)

14. Joseph, M., Tabata, H., Kawai, T.: P-type electrical conduction in ZnO thin films by Ga and N codoping. Jpn. J. Appl. Phys. (1999). doi:10.1143/JJAP.38.L1205

15. Ozg̈r, U., Alivov, Y.I., Liu, C., Teke, A., Reshchikov, M.A., Avrutin, V., Cho, S.J., Mork, H.: A comprehensive review of ZnO materials and devices. J. Appl. Phys. (2005). doi:10.1063/1. 1992666

16. Ohtomo, A., Tsukazaki, A.: Pulsed laser deposition of thin films and superlattices based on ZnO. Semicond. Sci. Technol. (2005). doi: $10.1088 / 0268-1242 / 20 / 4 / 001$

17. Schmidt, R., Rheinlnder, B., Schubert, M., Spemann, D., Butz, T., Lenzner, J., Kaidashev, M.E., Lorenz, M., Rahm, A., Semmelhack, H.C., Grundmann, M.: High electron mobility of epitaxial $\mathrm{ZnO}$ thin films on c-plane sapphire grown by multistep pulsedlaser deposition. Appl. Phys. Lett. 82, 3901-3903 (2003)

18. Wang, F., Liu, B., Zhang, Z., Yuan, S.: Synthesis and properties of Cd-doped ZnO nanotubes. Physica E 41, 879-882 (2009)

19. Prasad, G.K.: Decontamination of 2-chloro ethyl phenyl sulphide using mixed metal oxide nanocrystals. J. Sci. Ind. Res. 69, 835-840 (2010)

20. Prasad, G.K.: Silver ion exchanged titania nanotubes for decontamination of 2-chloroethyl phenyl sulphide and dimethyl methyl phosphonate. J. Sci. Ind. Res. 68, 379-384 (2009)

21. Sadeghi, M., Hosseini, M.H., Tafi, H.: Synthesis and characterization of $\mathrm{ZnCaO}_{2}$ nanocomposite catalyst and the evaluation of its adsorption/destruction reactions with 2-CEES and DMMP. Int. J. Bio-Inorg. Hybrid. Nanomater. 2, 281-293 (2013)

22. Sadeghi, M., Hosseini, M.H.: Nucleophilic chemistry of the synthesized magnesium oxide (magnesia) nanoparticles via microwave@sol-gel process for removal of sulfurous pollutant. Int. J. Bio-Inorg. Hybrid. Nanomater. 3, 175-182 (2012)

23. Sadeghi, M., Hosseini, M.H.: A novel method for the synthesis of $\mathrm{CaO}$ nanoparticle for the decomposition of sulfurous pollutant. J. Appl. Chem. Res. 7, 39-49 (2013)

24. Mahato, T.H., Prasad, G.K., Singh, B., Batra, K., Ganesan, K.: Mesoporous manganese oxide nanobelts for decontamination of sarin, sulphur mustard and chloro ethyl ethyl sulphide. Microporous Mesoporous Mater. 132, 15-21 (2010)

25. Bhasker-Raj, V., Tomar, M., Nimal, A.T., Parmar, Y., Sharma, M.U., Gupta, V.: ZnO surface acoustic wave sensor for the enhanced detection of DMMP. Solid State Phenom. 185, 69-72 (2012)

26. Nikmaram, F.R., Najafpour, J.: Ashrafi Shahri, M.: decontamination of DMMP by adsorption on $\mathrm{ZnO}$, a computational study. J. Phys. Theor. Chem. 9, 11-15 (2012)

27. Scharrer, M., Yamilov, A., Wu, X., Cao, H., Chang, R.P.H.: Ultraviolet lasing in high-order bands of three-dimensional $\mathrm{ZnO}$ photonic crystals. Appl. Phys. Lett. (2006). doi:10.1063/1. 2203939

28. Shen, H., Shan, C.X., Li, B.H., Xuan, B., Shen, D.Z.: Reliable self-powered highly spectrum-selective $\mathrm{ZnO}$ ultraviolet photodetectors. Appl. Phys. Lett. (2013). doi:10.1063/1.4839495

29. Lee, W.C., Liu, K.S., Lin, I.N.: Nonlinear electrical properties of $\mathrm{ZnO}$ varistors fast-fired by using millimeter-wave sintering process. J. Mater. Sci. 35, 4841-4847 (2000)

30. Tang, H., Cheng, Z., Zhu, H., Zhang, M.: Effect of acid and base sites on the degradation of sulfur mustard over several typical oxides. Appl. Catal. B Environ. 79, 323-333 (2008)

31. Vafaee, M., Sasani Ghamsari, M.: Preparation and characterization of $\mathrm{ZnO}$ nanoparticles by a novel sol-gel route. Mater. Lett. 61, 3265-3268 (2007)

32. Karami, H.: Investigation of sol-gel synthesized $\mathrm{CdO}-\mathrm{ZnO}$ nanocomposite for CO gas sensing. Int. J. Electrochem. Sci. 5, 720-730 (2010)

33. Arup, R., Jayanta, B.: Microwave-assisted synthesis and characterization of $\mathrm{CaO}$ nanoparticles. Int. J. Nanosci. 10, 413-418 (2011)

34. Sadeghi, M., Hosseini, M.H.: The decontamination of methamidophos as an organophosphorus insecticide on the magnetite $\left(\mathrm{Fe}_{3} \mathrm{O}_{4}\right)$ nanoparticles/Ag-NaY faujasite molecular sieve zeolite (FMSZ) composite. Int. J. Bio-Inorg. Hybrid. Nanomater. 2, 517-524 (2013)

35. Debye, P., Scherrer, P.: Interference in irregularly oriented particles in Röntgen light. Phys. Z. 17, 277-283 (1916)

36. Jain, A., Panwar, S., Kang, T.W., Kumar, S.: Effect of zinc oxide concentration on the core-shell $\mathrm{ZnS} / \mathrm{ZnO}$ nanocomposites. J. Mater. Sci. Mater. Electron. 24, 5147-5154 (2013)

37. Singh, A., Kumar, R., Malhotra, N.: Preparation of $\mathrm{ZnO}$ nanoparticles by solvothermal process. Technol. Latest Trends $\mathbf{4}$, 49-53 (2012)

38. Peng, X., Palma, S., Fisher, N.S., Wong, S.S.: Effect of morphology of $\mathrm{ZnO}$ nanostructures on their toxicity to marine algae. Aquat. Toxicol. 102, 186-196 (2011)

39. Mehrizad, A., Gharbani, P.: Study on catalytic and photocatalytic decontamination of (2-chloroethyl) phenyl sulfide with nano$\mathrm{TiO}_{2}$. Int. J. Nanosci. Nanotechnol. 7, 48-53 (2011)

40. Kanyi, C.W., David, C.D., Schulte, J.T.: Nucleophilic chemistry of X-type faujasite zeolites with 2-chloroethyl ethyl sulfide (CEES), a simulant of common mustard gas. Microporous Mesoporous Mater. 124, 232-235 (2009) 